\title{
Doğu Karadeniz Kıyılarında Sel ve Fırtınaların T-Mahmuzlar Üzerinde Oluşturduğu Hasarlar ve Su Kalitesi Değişimlerine Etkilerinin Araştırılması
}

\author{
Veli SÜME ${ }^{1 *}$ Bülent VEREP ${ }^{2}$ \\ ${ }^{1}$ Recep Tayyip Erdoğan Üniversitesi, Mühendislik Fakültesi, İşaat Müh. Bl, Rize, Türkiye \\ ${ }^{2}$ Recep Tayyip Erdoğan Üniversitesi, Su Ürünleri Fakültesi, Rize, Türkiye.
}

Atıf yapmak için: Süme, V. \& Verep, B. (2021). Doğu Karadeniz Kıyılarında Sel ve Fırtınaların T-Mahmuzlar Üzerinde Oluşturduğu Hasarlar ve Su Kalitesi Değişimlerine Etkilerinin Araştırılması. Anadolu Çev. ve Hay. Dergisi, 6(4), 627-634.

How to cite: Süme, V. \& Verep, B. (2021). On the Eastern Black Sea Coasts, Investigation of Floods, Storms and the Effects of Water Quality Changes on T-groins. J. Anatolian Env. and Anim. Sciences, 6(4), 627-634.

: https://orcid.org/0000-0001-8251-2461 (iD): https://orcid.org/0000-0003-4238-8325

\section{*Corresponding author:}

Veli SÜME

Recep Tayyip Erdoğan Üniversitesi,

Mühendislik Fakültesi, İnşaat Müh. Bl, Rize,

Türkiye

凶: veli.sume@erdogan.edu.tr
Öz: Bu çalışmada, deniz kıyılarının korunması, kıyının zamanla kumla dolması sonucu doğal bir plaj oluşturarak kıyının rehabilite edilmesi amacıyla çeşitli şekillerde inşa edilen mahmuzlar incelenmiştir. $\mathrm{Bu}$ inceleme esnasında özellikleri, çeşitli sel ve firtınalar gibi doğa olayları sebebiyle etkileşimleri ve mahmuz içlerinde mevsime bağlı sıcaklık değişimleri ve yosunlaşma gibi sonuçları olan su kalite değişimleri üzerinde durulmuştur. Doğu Karadeniz bölgesinde sadece T-mahmuz olarak yapılan bu kıyı koruma yapıları çeşitli sayılarda ard arda sıralanarak kıyı boyunca gruplar halinde inșa edilmișlerdir. Yan yana iki T-mahmuz'un arasında kalan su havuzunun 15 ile 30 yıllık bir süreç boyunca yavaş yavaş kumla dolması ve daha sonra doğal bir kumsalın oluşması beklenmekle beraber bu süreç boyunca zaman zaman sel ve firtınalar sonucu kıyı yapılarında hasarlar oluşmakta su kalitesinde değişiklikler meydana gelmektedir. Bu bağlamda, yaklaşık 40 km'lik bir sahil şeridinde, Trabzon-Of Soğukpınar da 8'li grup, Kıyıcıkta 13'lü grup, Eskipazar da 10'lu grup, Rize İyidere de 8'li grup, İyidere merkez de 4'lü grup, Sarayköy ve Alipaşa da 2'li grup, Balıkçılarda 5'li grup, Limanköy de ise, 4'lü grup olmak üzere toplam 56 adet T-mahmuzun yerinde inceleme ve gözlemleri yapılmış olup T-mahmuz sistemlerinde oluşan hasarlar, mahmuzların havuzlarında mevsimsel olarak su kalite değişimleri nedeniyle oluşan çevresel problemler araştırılmıştır.

$\underline{\text { Anahtar kelimeler: Kıyı koruma, T-mahmuz, su kalitesi, sel, deniz firtınaları. }}$

\section{On the Eastern Black Sea Coasts, Investigation of Floods, Storms and the Effects of Water Quality Changes on T-groins}

*Sorumlu yazar:

Veli SÜME

Recep Tayyip Erdogan University, Faculty

of Engineering, Civil Eng. Department, Rize,

Turkey

凶: veli.sume@erdogan.edu.tr

\begin{abstract}
In this study, spurs constructed in various ways in order to protect the sea coasts and to rehabilitate the coast by creating a natural beach as a result of filling the coast with sand over time were examined. During this study, water quality changes, which have characteristics, interactions due to natural events such as various floods and storms, and seasonal temperature changes and algae in the spurs, were emphasized. These coastal protection structures, which were built only as T-spurs in the Eastern Black Sea region, were built in groups along the coast in various numbers. Although it is expected that the water pool between two side-by-side T-spurs will gradually fill with sand over a period of 15 to 30 years and then a natural beach will form, during this process, coastal structures are damaged from time to time as a result of floods and storms, and changes in water quality occur. . In this context, on a $40 \mathrm{~km}$ coastline, 8 groups in Trabzon-Of Soğukpınar, 13 groups in Kıyıcık, 10 groups in Eskipazar, 8 groups in Rize İyidere, 4 groups in Rize İyidere center, 2 groups in Sarayköy and Alipaşa A total of 56 T-spurs, 5 in fishermen and 4 in Limanköy, were examined and observed.
\end{abstract}

Keywords: Shore protection, T-head groins, water quality, flooding, marine storms. 


\section{GíRiş}

Doğu Karadeniz sahil yolunun kıyı bandından geçmesinden dolayı Doğu Karadeniz kıyılarında daha önce plaj olarak kullanılan kıyısal alanlar ve balıkçılık alanları zarar görmüş, insanla deniz arasına önemli bir engel oluşturulmuştur. Ancak bölge insanının denizi sevmesi, geçimini denizden sağlaması ve rekreasyonel ihtiyaçların karşılanması için kıyıların rehabilite ve disipline edilmesi ihtiyacı oluşmuştur. Bu aşamadan sonra bölge kıyılarında balıkçı barınakları ve mendirekleri, T-mahmuzlar ve yapay plajlar projelendirilmiştir. T-mahmuzların inşa amacı genel olarak kıyının korunması, tabii plaj oluşumuna katkıda bulunulması ve insanların rekreasyonel ihtiyaçlarının karşılanması ve insanların denizle daha geniş ilişkide bulunmasını (dinlenme, yüzme, dalma, amatör veya profesyonel olta ve uzatma ağı balıkçılığı) sağlamaktır. Ancak bu tür kıyı koruma yapılarının dizaynında çoğunlukla oluşması muhtemel hasarlar ve kıyı suları kalitesi göz ardı edilmekte ve özellikle T-mahmuz sistemlerinde zaman zaman kıyı yapılarının iç kısımlarında su içinde ve kıyılarda aşırı yosunlaşma (lokal ötrofikasyon) ve düşük oksijen koşulları oluşabilmektedir. Bu çalışmayla konuyla ilgili literatürde üzerinde çok az durulan kıyı yapıları iç sularının su kalite değişimlerinin ortaya koyulması, T-mahmuzların dizaynında hasarlar ve su kalitesi açısından dikkat edilmesi gereken proje parametreleri ortaya koyulmaya çalışılacak ve literatürdeki önemli bir eksiklik giderilmiş olacaktır. Tmahmuz sistemleri iç havuz sularında düşük oksijen ve lokal ötrofikasyon olmaması için alınması gerekli önlemler ve Tmahmuz sistemleri ideal dizayn boyutları (T-mahmuz uzunluğu, genişliği, mahmuz baş uzunluğu, mahmuz sistemindeki su derinliği ve kıyı eğimi vb. parametreler) ve oluşan hasarlar irdelenmiştir. Böylece en değerli karasal alanlar olan kıyısal alanların dalga erozyonundan korunması ve doğal plaj oluşturulması aşamalarında kıyı alanlarından rekreasyonel ve ekonomik amaçlı yararlanılması için kıyı yapılarının yanlış dizaynı ve ortaya çıkabilecek kıyı suları kalite bozulmaları önlenmiş olacaktır.

Kıyısal bölge çevresel sorunlar ve kıyı hidrodinamiği konularında literatür tarandığında su kalitesi ile ilgili birçok çalışma yapıldığı görülmektedir. Ancak bunlardan çoğu içme suyu yani tatlı su ile ilgili olan iç sular ve yeraltı suları ile ilgili olduğu görülmektedir. Deniz ve okyanus gibi tuzlu olan kıyı suları ile ilgili ise, çok az çalışma yapılmıştır. Bunlar da genellikle plaj olarak kullanılan sahillerin korunması amacıyla yapılan dalgakıran veya mahmuz çalışmaları esnasında yapılan çalışmalardır. Mesela, Tauman, yıllar önce İsrail de Tel-Aviv sahillerinde halka açık plajların korunması amacıyla batık dalgakıranlar üzerine çalışmış ve bu konuyu çalışırken de su kalitesi ile ilgili de su kalitesi etüdü çalışmaları yapmıştır (Tauman 1976, Tauman 1975).
Martina ve ark. (2002) laboratuar ortaminda mahmuzlar üzerinde çalışmış ve boya kullanarak mahmuzlar civarındaki sediment hareketlerini ve hız değişimlerini incelemiş su kalitesinin nerelerde değişebileceğine de kısaca değinmiştir (Martina vd., 2002). Kerr (1995) ise, Kanada da 1930-1995 yıllarını kapsayan geniş kapsamlı bir literatür taraması yapmıştır. Hazırladığı 277 sayfalık teknik bir raporda tüm çalışmaları inceleyerek, su kalitesini etkileyen çevresel faktörlerin tamamını derleyerek bunları gruplandırmıştır. Çevresel faktörlerle birlikte su kalitesi kriterlerini de oluşturan ve günümüze de 1ş1k tutacak bir index geliştirmiştir (Kerr, 1995). Los Angeles çevre işleri dairesi (2001) Cabrillo plajında su kalitesi ile ilgili bir çalışma yaptırmış ve yayınlatmıştır (City of Los Angeles, 2001). Yine Los Angeles limanı mühendislik birimi (2006) Cabrillo plajında bakteriyolojik kirlilikle ilgili su kalitesi etüdü yaptırmış ve 86 sayfalık bir rapor yayınlatmıştır (Port of Los Angeles Engineering Division, 2006). Wyoming eyaleti sekreterliği de (2004), yüzeysel suların drenajı ve kalitesi ile ilgili kurallar ve düzenlemeleri içeren geniş kapsamlı bir rapor yayınlanmış ve yetkililere imzalattırılarak uygulanması sağlanmıştır (Office of the Secretary, "Water quality Rules and Regulations, 2004).

Massachusetts de (2004) körfez havzasında yapılan geniş kapsamlı bir proje çalışmasında yer altı suyu, derinlik ölçümü, kirlilik vb gibi arazi verilerini laboratuvara taşıyarak model çalışması yapmışlar yaptıkları çalışmalar ile birlikte su kalitesi etüdü de yapmışlar ve azot sınır değerlerini araştırmışlardır (University of Massachusetts Dartmouth School of Marine Science and Technology, Massachusetts Department of Environmental Protection, 2004). Tiny Township Lafontaine Beach Park'ta (2013) su sorunları ve su kalitesinin artırılmasında yardımcı olacak alternatif çözümler incelenmiştir. Mevcut mahmuzlar su kirliliğini artırdığı için kaldırılmasına karar verilmiş ve plaj temizlenerek suni besleme yapılmıştır. Böylelikle kıyı akıntılarının ve sediment taşınımının sürekliği sağlanarak su kalitesinin artırılmasına çalışılmıştır. Projenin sonuçları 243 sayfalık teknik rapor olarak yayınlanmıştır (Aqua Solutions 5 Inc. for the Township of Tiny, 2013).

Doğu Karadeniz bölgesinin dağlık yapısı ve yerleşimlerin kıyısal bölgelere yakın olmasından dolayı karayollarının deniz kıyılarının doldurularak yapılması ve dolayısıyla bu karayolun deniz dalgalarının tahribinden korunması amacıyla birçok kıyısal alanlarda mendirek, kıyı duvarları ve daha çok ise T-mahmuzlar inşa edilmiştir. Tmahmuzların inşası, tasarımı ve projelendirilmesi üzerine Doğu Karadeniz de özellikle Trabzon ve Rize kıyılarında inşa edilen kıyı gelişiminin etkileri üzerine bazı çalışmalar söz konusu olmuştur (Süme, V. (2007), Süme, V. (2003), APHA, AWWA, WPCF. (1992).

Ancak, dalga kıranlar civarında su kalitesi ile ilgili çalışmalar bir kaç adeti ((Tauman 1976, Tauman 1975), 
Aqua Solutions 5 Inc. for the Township of Tiny, 2013). geçmemektedir. Özellikle T-mahmuzlar civarındaki yani içinde ve dışında su kalitesi etüdü ile ilgili 2013 yılında Toronto da benzer bir çalışma sadece su sıcaklığı değişimi açısından yapılmıştır (Aqua Solutions 5 Inc. for the Township of Tiny, 2013). Ancak Türkiye'de ise buna benzer hiçbir çalışmaya henüz rastlanılamamıştır. Dolayısıyla insanlar için önemli bir rekreasyon alanı olan T-mahmuz denizel alanlarının mevsimsel su kalite değişimlerinin belirlenmesi önemli bir eksikliği giderecektir.

T-mahmuzların inşaası görev yapması ve kıyı koruma üzerine etkileri konusunda oldukça fazla çalışma mevcuttur. Bu konuda en çok araştırma Florida kıyılarında yapılmıştır. Thomson ve Swigler Florida Miami de, Ping ve Tiffany Tampa sahillerinde mevsimsel olarak $\mathrm{T}$ mahmuzların plaj oluşumuna etkileri üzerine bir çok çalışma yapmışlardır. Bu çalışmalarında inceledikleri T-mahmuzları inşaasında çoğunlukla taş malzeme kullanılmadan inşaa edilenler teşkil etmektedir. Fakat, çok az da olsa inceledikleri mahmuzların içinde taş malzeme ile inşaa edilen mahmuzlar da mevcut olduğu halde bunlar için de hasardan bahsetmemişlerdir.

Hanson ve Nicholas (2001) ve Hanson ve Kraus (2003) T ve L mahmuzlar civarında çalışmışlar ve kıyı ve mahmuz civarında oluşan erozyonu incelemişler, yayınladıkları teknik notta periyodik olarak incelenerek kontrol edilmesi gerektiğinden bahsetmişlerdir. Bodge ve ark. (2003) ise, kıyı yapılarında özellikle T-mahmuzlarda meydana gelen hasarların kiyı erozyonundan kaynaklandığını belirtmekle yetinmişlerdir. Bu sebeple, Tmahmuzlar ile ilgili özellikle taş gövde olarak inşaa edilen mahmuzların gövdelerinde meydana gelen hasar tespiti ile ilgili kapsamlı bir çalışmaya literatürde rastlanmamıştır (Hanson, H., and Nicholas, C.,K. (2001), Hanson, H., Kraus, N.C. (2003), Bodge, K. R. (2003), Ping, W., Tiffany M., R. (2009), Thomson, G., Swigler, D. (2013).

\section{MATERIAL AND METHOD}

$\mathrm{Bu}$ araştırmada Of-Trabzon Soğukpınar ile ÇayeliRize arasındaki yaklaşık 40 km'lik bir sahilde yerleştirilmiş T-mahmuz projelerindeki kıyısal yapı gelişimi ve değişimi, sel ve firtınalar sonrası oluşan hasarlar, mahmuzlar arasında oluşan havuzlarda mevsimsel olarak su kalite değişimleri nedeniyle oluşabilecek sorunlar ve kıyı yapılarına etkileri araştırılmıştır. Çalışma neticesinde T-mahmuz sistemlerinin kıyısal yapının şekillenmesindeki başarısı, mevcut kıyı yapıları üzerinde oluşan hasarlar açısından değerlendirmeler yapılmıştır.

Araştırma bölgesiyle ilgili olarak 2000 yılından bu yana gerçekleştirilen batimetrik ölçümler ve granülometrik malzeme analizleri yapılmaktadır (Süme 2007, Süme 2003). Bu gözlemler 1şığında bu tür T-mahmuz sistemlerinde dolma sürecinin yavaş işlediği, sahilin kum ile dolarak doğal plaj görünümünün oluşmadığı görülmüştür. $\mathrm{Bu}$ yüzden $\mathrm{T}$ mahmuzlarda oluşan hasarların takip edilmesi ve araştırma alanının mevsimsel su kalite değişimlerinin izlenmesi çok önemlidir. Çalışmada mahmuzlar arasında oluşan havuz içi mevsimsel su kalite değişimleri nedeniyle sıcaklık artışı, sığlaşma ve su dinamiğindeki yavaşlamalar yüzünden yosunlaşma ve sonrasında çürüme süreçleri neticesinde oksijen seviyesinde düşüşler olduğu gözlemlenmiş ve mahmuz sistemlerinde sel ve firtına sonrası oluşan hasarlar değerlendirilmiştir. Çalışmada, mahmuzlar arasındaki havuz içerisinde oksijensizlik ve yosunlaşma problemleri irdelenmiş oluşum dönemleri ve koşulları, oluşan hasarların oluşum nedenleri açıklanmıştır.

Mahmuz sisteminin çevresinde yer alan akarsu nehir ağzı, kanalizasyon ve karayolu drenaj suyu deşarj noktaları ve balıkçı barınaklarınca denize organik ve inorganik kirleticiler bırakılmaktadır. S1klıkla meydana gelen seller neticesinde akıntı ve dalgalar aracılığıyla bu kirleticilerin mahmuz sistemi havuzlarına taşınması ve birikmesi nedeniyle, mahmuzlar arasındaki havuzların içerisinde su kalite bozulmalarının yanı sıra daha çok yaz mevsimlerinde ve yağış veya sel koşullarında oluştuğu tespit edilmiştir.

Kıyılarda inşa edilen mahmuzlar, kıyı boyu katı madde hareketini engellemek, miktarını azaltmak, kıyıda meydana gelen erozyonu önlemek ve yeni bir kıyı çizgisi veya koruyucu kumsal oluşturmak amacıyla, genellikle kıyıya dik olarak inşa edilen kıyı yapılarıdır. Memba tarafındaki malzeme hareketini azaltıp, liman ve balıkçı barınaklarının dolmalarını önlemek ve doğal plaj elde etmek amaciyla da kullanılırlar.

Kıyı çizgisi boyunca oluşan katı madde taşınımı ile mahmuzlar arasındaki etkileşim oldukça karmaşık bir yapıya sahiptir. Bu nedenle mahmuzların projelendirilmelerinde çok kesin esaslar koyabilmek, ancak çok uzun çalışmalar sonucu mümkün olabilmektedir. Çalışmalardan anlaşılmaktadır ki bir mahmuz inşa edilirken, mahmuzun kıyıya olan bağlantısı sağlam yapılmalı ve en az 5-7 metre kara içine girmelidir. Mahmuzlar öyle yerleştirilmelidir ki, verilecek açıklıklarda, kıyıya ve kıyıya doğru hareket halindeki malzeme mahmuz yapılarının kafalarını aşıp, dışarı çıkmamalıdır. Gruplar halinde bir sistem oluşturularak birinden kaçan malzeme diğeri tarafından yakalanabilecek şekilde tasarlanmalıdır. $\mathrm{Bu}$ yüzden boyut analizinde dalgaların doğrultusu ve yönü, rüzgar ve meteorolojik unsurlar, kıyı morfolojisi, depremsellik, sediment taşınımı ve yönü, kullanılacak malzeme türü ve kalitesi, oluşabilecek hasarlar ve su kalitesi de dikkate alınacak en önemli faktörlerdendir.

Mahmuzların uzunlukları ortalama 30-200 metre civarında değişir. "T" mahmuzlar ise, kıyı malzemesini her iki tarafindan tutar ve düz mahmuzlara oranla daha iyi bir 
koruma sağlarlar. Kıyının uzun bir kesimini korumak için beraber işleyen bir dizi mahmuza "mahmuz sistemi" adı verilebilir. Mahmuzlar gerek yapısal gerekse işlevsel olarak dalgakıranlardan farklıdırlar. Dalgakıranlar daha ağır ve büyük elemanlardan meydana gelmiş olup daha geniş ve yüksektirler.

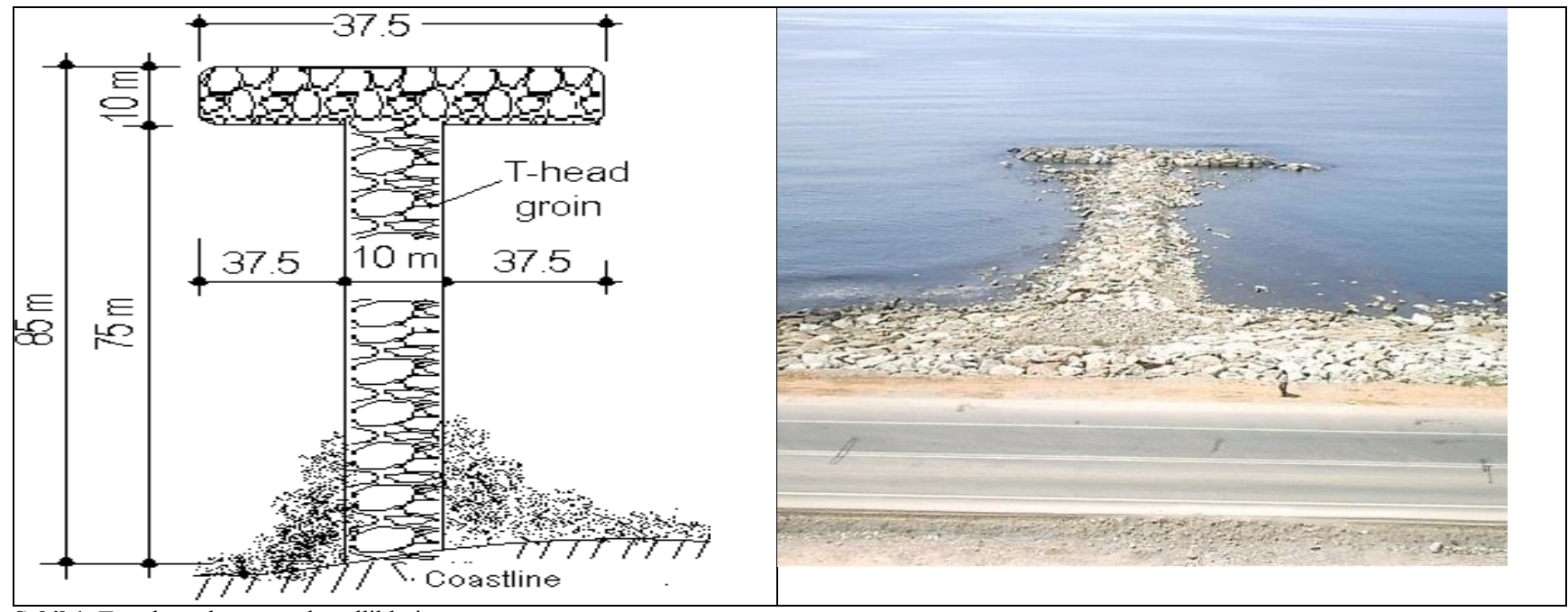

Şekil 1. T-mahmuzların genel özellikleri.

Figure 1. The general properties of T-groins.

Bir mahmuzun uzunluğu, kıyısal katı madde taşınım miktarını belirler ve mahmuzun çalışma şekli yan yana bulunan mahmuzlar arasındaki açıklığın belirlenmesinde kullanılır. Mahmuzlarda kıyıya doğru taşınım artarken, açığa doğru taşınım azalır ve kıyının aşağıya doğru taşınması bir nevi önlenir. Bu durum, kıyıya doğru taşınan kumların bir tepecik oluşturmasına neden olur.

Kıyı koruyucu yapıların projelendirilmesinde en önemli konu, güvenilir yöresel bilgilerdir. Projelendirmeye temel olabilecek herhangi bir ön tasarı ortaya koymadan önce yöreye ilişkin hakim rüzgarlar, ekstrem dalgalar, kumsal oluşumlar, en az $10 \mathrm{~m}$ derinliğe kadar kıyı topografyası hakkında mümkün olan en geniş bilgi toplanmalıdır. Koruyucu kıyı yapısı olarak hangi tip seçilirse seçilsin büyük firtınalar esnasında az çok hasar görmesi kaçınılmazdır. Dolayısıyla bunların periyodik bakımı mutlaka yapılmalıdır.

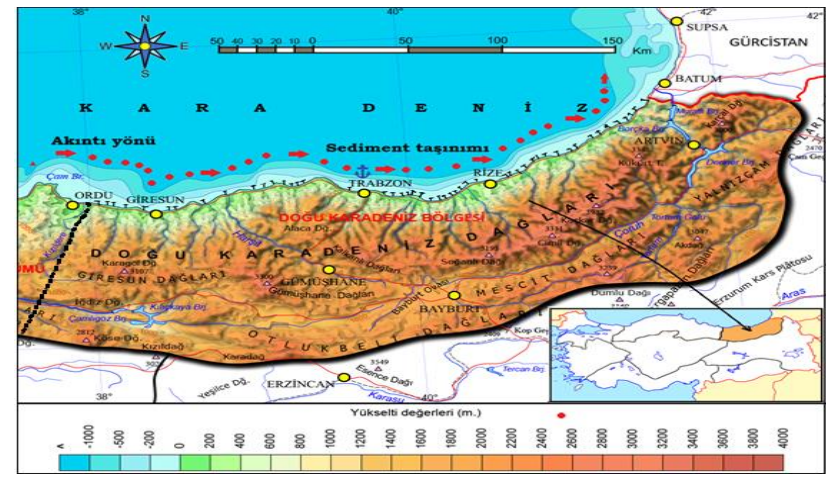

Sekil 2. Doğu Karadeniz Sahilinde T-mahmuzların (Ordu Sarp arasında) kıyı boyu dizilişi

Figure 2. Line-up T-groins along the coast, (between Ordu-Sarp) on the Eastern Black Sea.
Kıyı yapıları inşa edileceği zaman, bölgenin şartları dikkatli bir biçimde incelenmelidir. Kıyıdaki hakim dalga yönü ve buna bağlı olarak da, çok önemli olan katı madde taşınım yönü belirlenmelidir. Eğer kıyıda bir yapı varsa, katı madde taşınımının etkin olduğu yapının memba tarafı dolmaya başlayacak ve yapının mansap tarafı ise, erozyona maruz kalacaktır. Bu durum seri halde inşa edilen yapılarda daha değişik sonuçlar vermektedir. Yine yapılan incelemeye göre, mahmuzların boy, aralık ve başlık uzunlukları hakkında kesin sonuçlar verilmediği ortaya çıkmıștır. Herhangi bir kıyıda, bir kıyı yapısı inşa edilmiş ise, kıyı çizgisi değişimini etkileyen faktörler; Dalga yüksekliği (H), Dalga periyodu (T), Dalga açısı ( $\alpha$ ), Taban eğimi $(\tan \beta)$, Dane çapı $\left(\mathrm{d}_{50}\right)$, Yapının boyu $\left(\mathrm{L}_{\mathrm{x}}\right)$, Yapılar arası mesafe $\left(\mathrm{L}_{\mathrm{G}}\right)$, Kıyı boyu katı madde taşınım miktarı (Q), şeklinde verilmiştir.

Diğer yandan mahmuzlar her ne kadar kıyı bölgesinin karasal alanını korumak ve tabii plaj olușumunu sağlamak için dizayn edilseler de mahmuzların suyun içerisine doğru yerleştirilmesi noktasında ve deniz alanına etkisi üzerine çok az çalışma mevcuttur. Doğu Karadeniz Bölgesi içerisinde deniz kıyısı olan illerde yaklaşık olarak 355 adet T-mahmuz bulunmakta olup, kıy dolguları nedeniyle bunların sayıları günden güne değişmektedir (Tablo 1).

Özellikle kıyı boyunca inșa edilen T-mahmuz sistemlerinde ardarda siralanan T-mahmuz gövdeleri arasında kalan su kütlelerinin hidrodinamiği, su kalitesi ve sedimantasyon özellikleri oldukça önem arz etmektedir. Nitekim zaman içersin de mahmuzların iç bölgelerinin sedimantasyon süreciyle dolması, dalga, akıntı ve çeşitli karışımlarla etkilenmesi ve tüm bunların etkisi altında su kalitesi değişimi kaçınılmazdır. Özellikle yaz aylarında hidrodinamik süreçlerin yavaşladığı ve su sıcaklığının yükseldiği dönemlerde insan, kıyı ve diğer çevresel etkilerle bu ortamların oksijensiz veya düşük oksijenli koşullara ulaşması ortaya çıkmaktadır. Bazı dönemlerde 
ise, özellikle mevsim geçişleri (yaz-bahar) yüksek organik kökenli maddelerin akıntı, dalga ve diğer sebeplerle bu alanlara taşınması, birikmesi ve nütrient zenginleşmesi sonucu ötrofikasyon (alg patlaması ya da yosunlaşma) süreçleri oluşabilmektedir.

Tablo 1. Doğu Karadeniz Bölgesinde (Ordu-Giresun-Trabzon-Rize ve Artvin) T-mahmuzların illere göre dağılımı.

Table 1. Distribution of T- groins by provinces in the Eastern Black Sea Region (Ordu-Giresun-Trabzon-Rize and Artvin).

\begin{tabular}{|c|c|c|c|}
\hline İl & İlçe & Sayı & Toplam \\
\hline & Fatsa & 43 & \multirow{3}{*}{115} \\
\hline \multirow[t]{2}{*}{ Ordu } & Merkez & 50 & \\
\hline & Gülyalı & 22 & \\
\hline \multirow[t]{6}{*}{ Giresun } & Merkez & 16 & \multirow{6}{*}{69} \\
\hline & Keşap & 7 & \\
\hline & Espiye & 8 & \\
\hline & Tirebolu & 12 & \\
\hline & Görele & 20 & \\
\hline & Eynesil & 6 & \\
\hline \multirow{10}{*}{ Trabzon } & Beşikdüzü & 3 & \multirow{10}{*}{122} \\
\hline & Vakfikebir & 5 & \\
\hline & Çarşıbaşı & 23 & \\
\hline & Akçaabat & 8 & \\
\hline & Merkez & 8 & \\
\hline & Yomra & 7 & \\
\hline & Arsin & 17 & \\
\hline & Araklı & 10 & \\
\hline & Sürmene & 10 & \\
\hline & Of & 31 & \\
\hline \multirow{6}{*}{ Rize } & İyidere & 14 & \multirow{6}{*}{49} \\
\hline & Merkez & 2 & \\
\hline & Çayeli & 10 & \\
\hline & Pazar & 16 & \\
\hline & Ardeșen & 2 & \\
\hline & Findıklı & 5 & \\
\hline \multirow[t]{3}{*}{ Artvin } & Arhavi & 0 & \multirow{3}{*}{0} \\
\hline & Hopa & 0 & \\
\hline & Kemalpaşa & 0 & \\
\hline
\end{tabular}

Çalışmada 1 yıl boyunca sel ve firtınalar nedeniyle mahmuz sistemlerinde oluşan hasarlar tespit edilmiş ve belirlenen istasyonlarda su kalite veya kirliliğiyle ilgili oluşabilecek çevresel problemlerin izleme çalışmaları yapılmıştır. Bu araştırma kapsamında bulunan 9 ayrı T-mahmuz sisteminde bulunan toplam 56 adet Tmahmuz gövdesinde sel ve firtına gibi önemli meteorolojik olaylar sonrası oluşan hasarlar yerinde tespit edilmiştir. $\mathrm{Su}$ kalitesi çalışmaları da yine yerinde gözlem yapılarak bulanma ve yosunlaşma varlığının tespitiyle gerçekleştirilmiştir.

Bu çalışmada, Doğu Karadeniz'de, Trabzon ili Soğukpınar mevkiinde 8, Of ilçesi Kıyıcık ve Eskipazar mevkiinde 23 ve Rize ili İyidere ilçesinde 8 tane, Sarayköy 2, Alipaşa 2, Balıkçılar 5, Limanköy 4 olmak üzere inşa edilen toplam 56 adet $\mathrm{T}$-mahmuz incelenmiş ve aşağıdaki hususlar elde edilmiştir (Tablo 3).

Hasar Tespitine Ait Uygulama Aşamaları: $\mathrm{Bu}$ çalışma, Trabzon-Of Soğukpınar'dan Rize-Çayeli'ne kadar olan bölgede 9 grup mahmuz sisteminde bulunan 56 adet mahmuz üzerinde yapılmıştır. Hasar tespiti ve su kalitesi etüdü çalışmalarına aynı anda başlanmış ve mevsimsel peryotlarla devam edilmiştir. Hasar tespitinin dışında, mahmuzların plaj oluşumuna katkıları ile ilgili çalışmalar yaz ve kış profili olarak yapıldıklarından hasar tespiti çalışmaları da yaz ve kış sezonu olmak üzere gerçekleştirilmiştir. Hasar tespitinde önce batimetrik derinliklere göre NET Cad ile tesviye eğrileri elde edilecek ve daha önceden alınıp aynı programla çizilmiş olan 2013 yılı batimetrik tesviye eğrileri ile kıyaslanmıştır. Sonra mahmuz civarlarına yerinde inceleme ve gözlemler yapılarak T-mahmuz gövdelerinden kopan ve ayrılan taşlar belirlenecektir. Bu malzemeler tahmini ağırlıklarına göre kategorize edilecektir. En sonunda yapilan bu tespitler resim ve grafiklerle krokileştirilip elde edilen sonuçlar yorumlanacaktır. Aşağıda çalışma alanı içerisinde (Şekil 7) günümüzdeki durumu görülen mahmuzun görev yaptığı ve hasardan etkilendiği kafasının dağıldığı ama buna rağmen kum biriktirmeye başladığı görülmektedir. Diğer bir resimde ise (Şekil 8) görev yapmayan ve kafası dağılmış ve kum biriktirmeyen bir mahmuz görülmektedir.

Tablo 3. Calıșma alanındaki T-mahmuzların bulundukları yerler ve sayılar1.

Table 3. Locations and numbers of T-groins in study area.

\begin{tabular}{lllc}
\hline İl & İlçe & Mevki & Sayı \\
\hline \multirow{3}{*}{ Trabzon } & Of & Soğukpınar & 8 \\
& Of & Kiyıcık & 13 \\
& Of & Eskipazar & 10 \\
\hline \multirow{4}{*}{ Rize } & İyidere & Hazar & 8 \\
& İyidere & Merkez & 4 \\
& İyidere & Sarayköy & 2 \\
& Merkez & Alipaşa & 2 \\
& Çayeli & Balıçıllar & 5 \\
\hline TOPLAM & Çayeli & Limanköy & 4 \\
\hline
\end{tabular}

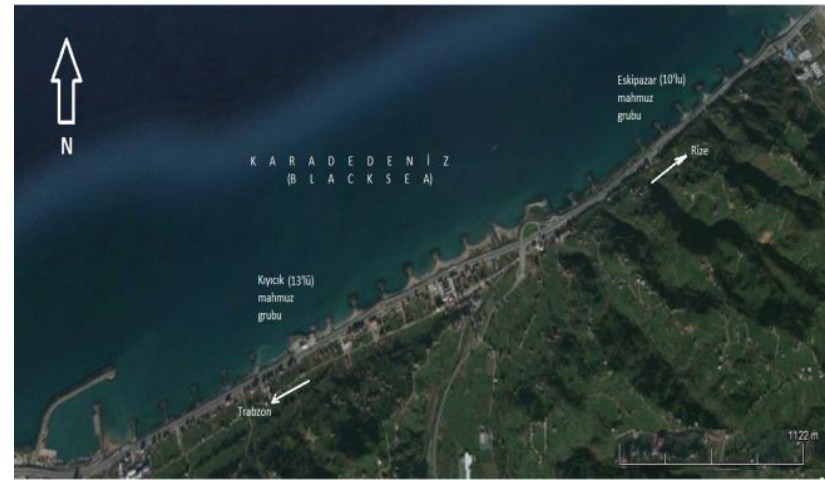

Şekil 3. Çalışma alanından T-mahmuz görüntüleri (Kıyıcık ve Eskipazar Grubu-Hasar tespiti için)

Figüre 3. T-groins images from the study area (for Kıyıcık and Eskipazar Group-Damage Detection)

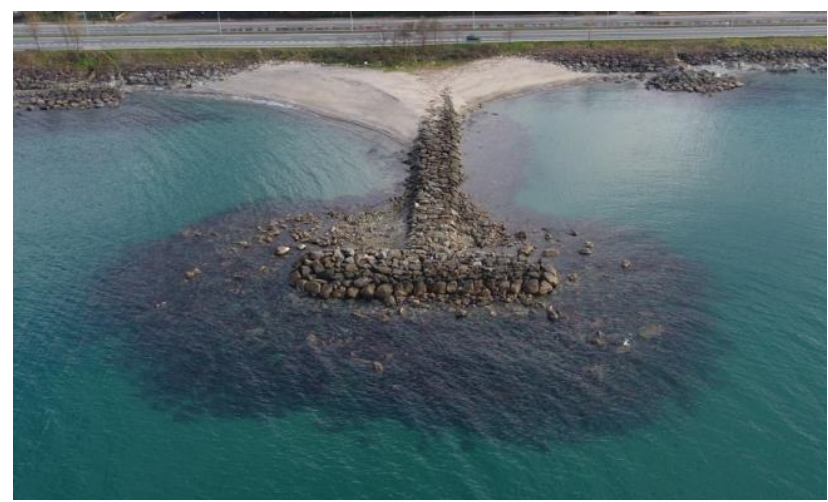

Şekil 4. Çalıșma alanında görev yapan hasarlı T-mahmuz. Figure 4. Damaged and functional T-spur in working area. 


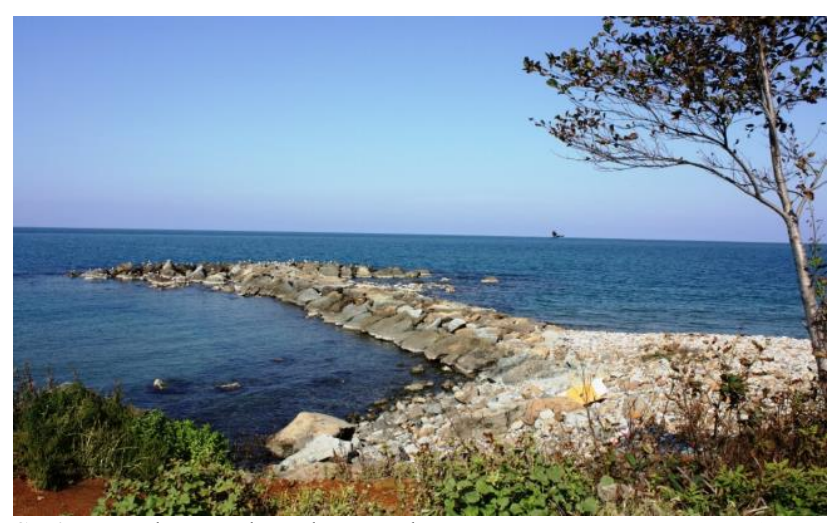

Şekil 5. Çalışma Alanında Hasarlı ve Görev Yapmayan T-mahmuz. Figure 4. Damaged and non functional T-spur in study Area.

Tablo 2. Trabzon / Of Kiyıcık 13'lü T-mahmuz gurubu yıllara göre (2003-2013) batimetrik değişim

Table 2. Trabzon / Of Kiyıc1k T-groin group with13, by years (20032013) bathymetric change.

\begin{tabular}{|c|c|c|c|c|c|c|c|}
\hline \multirow{2}{*}{$\begin{array}{c}\text { T- } \\
\text { Mahmuz }\end{array}$} & \multicolumn{2}{|c|}{2003} & \multicolumn{2}{|c|}{2009} & \multicolumn{2}{|c|}{2013} & \multirow[b]{2}{*}{$\begin{array}{l}\text { dane çap1 } \\
(\mathrm{mm})\left(\mathrm{d}_{50}\right)\end{array}$} \\
\hline & $\begin{array}{c}\text { Sol } \\
\text { Topuk }\end{array}$ & $\begin{array}{c}\text { Sağ } \\
\text { Topuk }\end{array}$ & $\begin{array}{c}\text { Sol } \\
\text { Topuk }\end{array}$ & $\begin{array}{c}\text { Sağ } \\
\text { Topuk }\end{array}$ & $\begin{array}{c}\text { Sol } \\
\text { Topuk }\end{array}$ & $\begin{array}{c}\text { Sağ } \\
\text { Topuk }\end{array}$ & \\
\hline T1 & -1.4 & -1.6 & -0.8 & -0.95 & 0.55 & 0.45 & 0.85 \\
\hline $\mathrm{T} 2$ & -0.1 & -0.8 & 0 & -0.2 & 0.7 & 0.5 & 2 \\
\hline T3 & -1.55 & -1.45 & -1 & -0.9 & 0.55 & 1 & 0.88 \\
\hline $\mathrm{T} 4$ & 0 & -1.2 & 0.2 & -0.9 & 0.85 & 1 & 1 \\
\hline T5 & -0.6 & -0.5 & -0.1 & -0.1 & 1.25 & 1.75 & 8 \\
\hline T6 & -0.5 & -0.7 & 0.2 & 0.1 & 2 & 2 & 6.5 \\
\hline $\mathrm{T} 7$ & -1 & -1 & 0 & 0 & 1.9 & 2 & 1.94 \\
\hline T8 & -0.8 & -1 & -0.1 & 0 & 1.5 & 1.35 & 4 \\
\hline Т9 & -0.8 & -0.8 & 0.2 & 0.3 & 0.9 & 1 & 20 \\
\hline $\mathrm{T} 10$ & -1.1 & -1 & 0.45 & 0.4 & 0.75 & 0.6 & 0.97 \\
\hline T11 & 0.4 & 0.35 & 0.55 & 1.1 & 1.1 & 1.5 & 0.76 \\
\hline $\mathrm{T} 12$ & 1.1 & 1.2 & 1 & 1.1 & 0.9 & 1.5 & 0.63 \\
\hline $\mathrm{T} 13$ & 1 & 1 & 1.2 & 1.15 & 0.85 & 1.4 & 0.57 \\
\hline
\end{tabular}
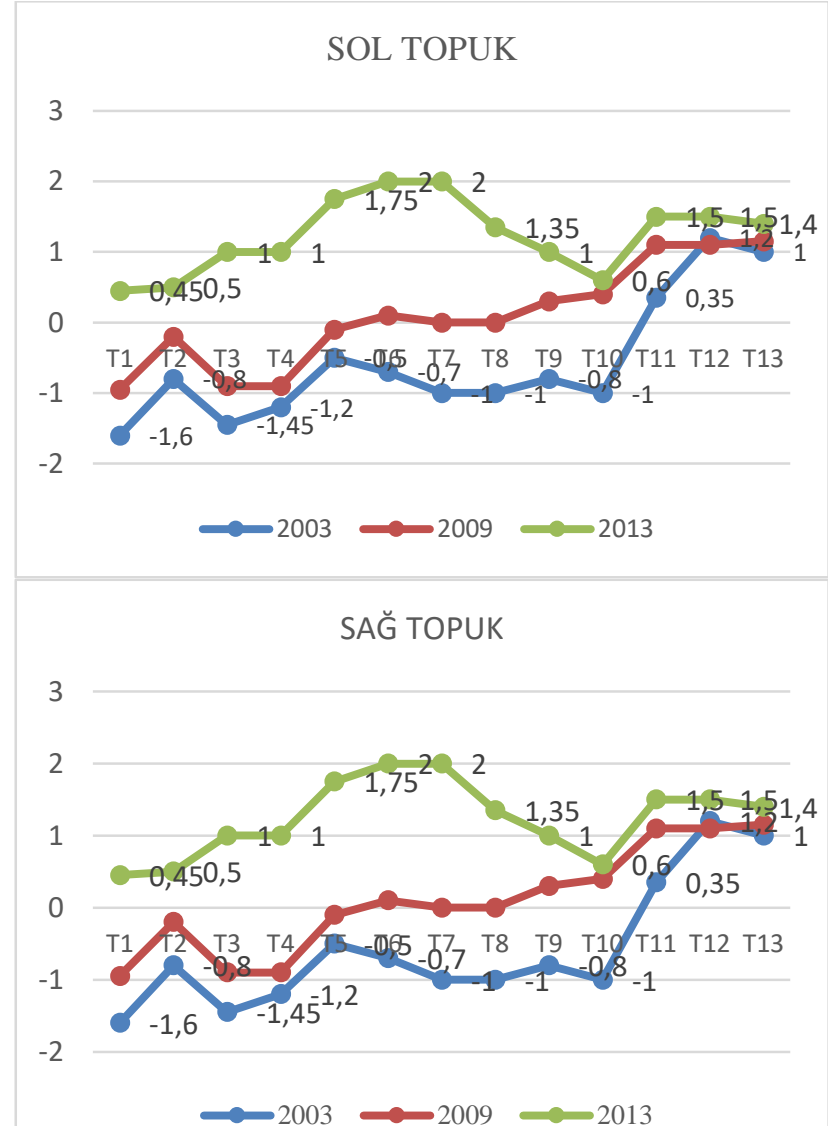

Şekil 6. Trabzon Of Kıyıcık T-mahmuz grubu (2003-2013) batımetrik değişim.

Figüre 6. Trabzon Of Kıyıcık T-Spur group (2003-2013) bathymetric change.

\section{SONUÇLAR VE DEĞERLENDİRME}

Özellikle dalga ve akıntıların düşük düzeyde olduğu kış ve yaz dönemlerinde, görülen en önemli problem mahmuzlar arasındaki havuzlar içerisinde organik, inorganik ve bakteriyolojik kirlilikle birlikte yaşanan oksijensizlik ve yosunlaşmadır. Diğer taraftan, bölgede sık sık meydana gelen seller, mahmuz sisteminin çevresinde yer alan akarsu nehir ağzı, kanalizasyon ve karayolu drenaj suyu deşarj noktaları ve balıkçı barınaklarınca denize bırakılan organik ve inorganik kirleticilerin akıntı ve dalgalar aracılığıyla mahmuz sistemi havuzlarına taşınmakta, yılın belirli dönemlerinde su kalite bozulmalarına sebebiyet vermektedir.

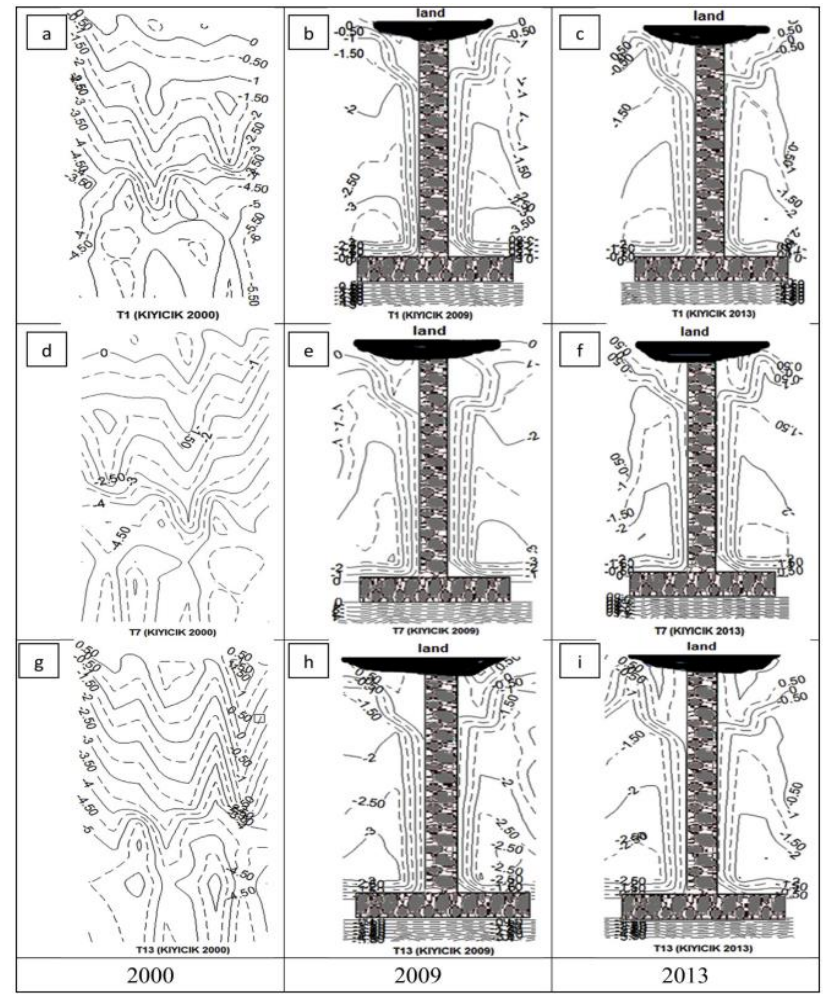

Şekil 7. Trabzon Of Kıyıcık T-mahmuz gurubu (2003-2013) izohips eğrileri değişimi.

Figüre 7. Trabzon Of Kıyıck T-groin group (2003-2013) izohips curves change.

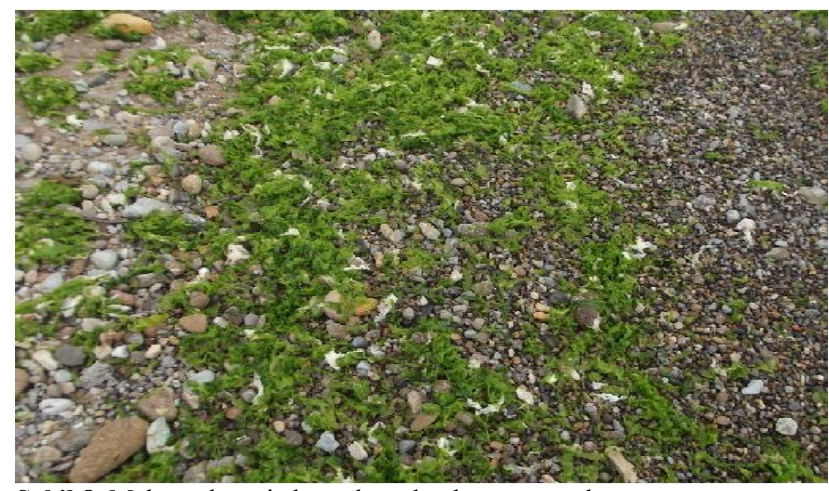

Şekil 8. Mahmuzların iç kısımlarında oluşan yosunlaşma.

Figüre 8. The seaweed formed in the interior of the spurs. 


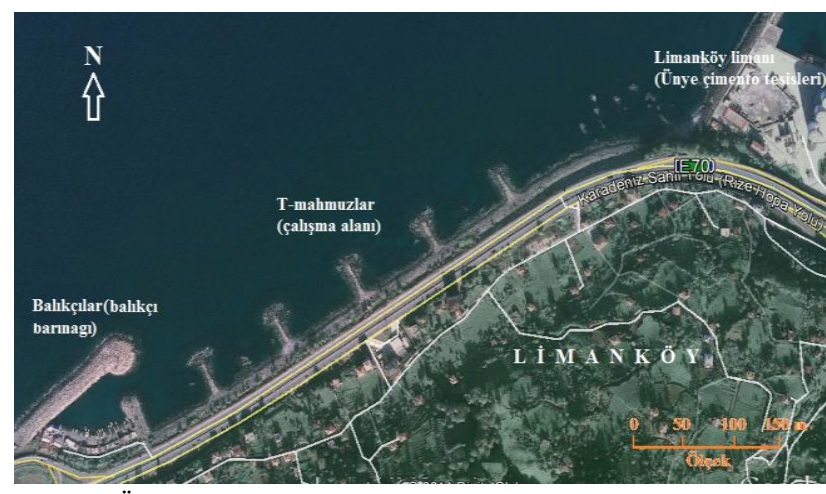

Şekil 9. Örnek çalışma alanının uydu görüntüsü (Limanköy Grubu-Su Kalitesi ve Hasar Tespiti İçin).

Figüre 9. Satellite image of sample workspace (for Limanköy Groupwater quality and damage detection)

Yerinde mahmuz sistemlerindeki her bir mahmuz su altına dalmak suretiyle gözlemle incelenmiş ve su altı kamerası ile fotoğraflanmıştır. Hasarlanan mahmuz malzemelerinden ve civarındaki agregalardan (kum-çakıl) numuneler alınmıştır. Bu numunelerin elek analizleri yapılmış ve dayanım testine tabii tutulmuştur. Böylece Trabzon ve Rize kıyılarında inşa edilmiş olan mahmuz sistemlerindeki T-mahmuzların kıyısal bölge suları üzerinde fiziksel, kimyasal ve organik kirlilik oluşturma potansiyeli ile mahmuz gövdelerinde oluşan hasarlar ve bunların nedenleri tespit edilmiş olacaktır.

\section{BULGULAR VE TARTIŞMA}

$\mathrm{Bu}$ çalışma gözlem ve deneye dayalı bir çalışma olup T-mahmuzlar civarında yapisal bozulmalar ve su kalitesi değişimleri yönüyle incelemeler yapılmıştır. Deniz taşkınları neticesinde T-mahmuzların gövdelerinde önemli oranda hasar meydana gelmektedir. Sellerden sonra ve deniz taşkınlarının hemen ardından T-mahmuzlar kontrol edilmeli meydana gelen yapısal hasarlar düzeltilmelidir.

Doğu Karadeniz bölgesinde Ordu sahillerinde 93, Giresun sahillerinde 90, Trabzon sahillerinde 149, Rize sahillerinde 47 olmak üzere, Ordu-Sarp sinır kapısı arasinda toplam 379 adet T-mahmuz bulunmaktadir. Genellikle mahmuz boyları 75 metre ve mahmuz aralıkları ise 150 metre olarak inşaa edilmişlerdir. Kıyılarda inşa edilen mahmuzlar, kıyı boyu katı madde hareketini engellemek, miktarını azaltmak, kıyıda meydana gelen erozyonu önlemek ve yeni bir kıyı çizgisi veya koruyucu kumsal yaratmak amaciyla, genellikle kıyıa dik olarak inşa edilen kıyı yapılarıdır. Ayrıca memba tarafındaki malzeme hareketini azaltıp, liman ve balıkçı barınaklarının dolmalarını önlemek amacıyla da işlev görmektedirler. $\mathrm{Bu}$ nedenle projelendirilmelerinde çok kesin esaslar koyabilmek, ancak çok uzun çalışmalar sonucu olabilir. Bir mahmuz inşa edilirken, mahmuzun kıyıya olan bağlantısı sağlam yapılmalı ve en az 6 metre kara içine girmelidir.
Mahmuzlar öyle yerleştirilmelidir ki, verilecek açıklıklarda, kıyıya ve kıyıya doğru hareket halindeki malzeme yapıların uçlarını aşıp, dışarı çıkmamalıdır. Bu durumda dalgaların doğrultusu, gelişimi ve malzeme hareketi dikkate alınacak en önemli faktörlerdir.

Bir mahmuzun uzunluğu, kıyısal katı madde taşınım miktarını belirler ve mahmuzun çalışma şekli yan yana bulunan mahmuzlar arasındaki açıklığın belirlenmesinde kullanılır. Mahmuzların uzunlukları ortalama 30-200 metre civarında değişir. Ortalama açıklıkları ise, genellikle mahmuz boyunun iki katı olarak alınırlar. Kıyının uzun bir kesimini korumak için beraber İşleyen bir dizi mahmuza "mahmuz sistemi" adı verilebilir.

Yapıların topuklarında ve çevrelerinde sediment depolanmasının gerçekleşmesinde etkili olan yapı faktörleridir. Bunlar dolmayı etkileyen tali mendireklerin varlığı, ani derinlik değişimi ve çevre ile ilgili faktörlerdir. Genellikle, Doğu Karadeniz Sahil Yolu bitirildikten sonra (2007 yılında) kıyıların korunması ve rekreasyon amacıyla inşaa edilen türlü türlü yapıların (balıkçı barınağı, çekek yeri, tahkimatlar, spor amaçlı tesisler, suni besleme vb.) kıyıların tabii dengesi üzerinde önemli rol oynamakta, oyulma ve dolma süreçlerini artırmaktadır. Yine bölgeden kontrolsüz kum alımı da çok önemli bir sorun olarak gözükmektedir. Kontrollü sediment birikimini sağlamak ve/veya artırmak amacıyla değişik yapısal önlemler alınabilir. Ayrıca mahmuz yapıları üzerinde dalgalardan kaynaklanan deformasyonların sediment depolanmasına olumsuz etkileri olmamaktadır. Çünkü mahmuzların kret kotları deniz seviyesinden $+0,50$ m yükseklikte olması gerekirken, bu yükseklik $1 \mathrm{~m}$. civarındadır. Yapıda oluşan deformasyonlar aslında yapının ideal seviyeye inmesine yardımcı olmuştur. Haliyle dalgaların kıyıya ulaşmaları kolaylaşmış ve sediment birikimine de olumlu katkı sağlamıştır. Civarda 2011 yılından sonra yürütülen ve devam eden bir proje sonuçlarına göre de yaklaşık 15-53 $\mathrm{cm}$ arasında bir deniz seviyesi değişimi olduğu görülmüştür. Bu duruma göre de seviye değişimi önemli bir parametre olarak gözükmektedir. Hülasa, özellikle geceleri ve fırtına sonrası aşırı değer artışı ölçülmektedir. Eş derinlik ölçümleri denizin nispeten durgun olduğu saatlerde yapıldığı için etkileşim artı veya eksi yönde pek fazla sonuca etkili olmamaktadır (Süme, 2011). Zamanla öyle ki bu süre çok değişken olmakla birlikte, Tmahmuzlar ve civarının tahminen otuz yıl içerisinde sediment tarafından örtülerek tamamen dolmaları ve kaybolmaları beklenmektedir.

Meydana gelen su kalite değişimleri nedeniyle de deniz canlıları büyük oranda etkilenmekte ve zaman zaman canlı kaybı olduğu gözlemlenmektedir. Aynı zamanda Tmahmuzlar civarı canlı popülasyonu için yaşam alanı konumundadır ve afet sonrası buralarda da bozulmalar 
olduğu ve etkileşimin devam ettiği gözlemlenmektedir. Mevcut mahmuzların düzensizliği nedeniyle çoğu görev yapmamaktadır. Hatta mahmuz sistemi içinde diğerlerini de etkilemek suretiyle hasar oranını artırmakta ve görev yapamaz hale getirmektedir. $\mathrm{Bu}$ çalışmaların neticesinde özellikle Doğu Karadeniz kıyılarında duble karayolun kıyı hattından geçirilmiş olması sebebiyle kıyı koruma yapılarının devamlı ve periyodik olarak gözlenlenmesi, hasar tespitlerinin raporlanması ve gerekli onarım veya koruma amaçlı önlemlerin alınması gerektiği anlaşılmıştır. Dolayısıyla gerek sivil ulaşım ve gerekse lojistik faaliyetlerin aksamaması açısından kıyı koruma yapılarının buradaki mahmuzların kıyıa etkileri veya kıyıdan etkileşimleriyle ilgili araştırma, inceleme ve gözlem çalışmalarına önem verilmesi gerekir.

\section{KAYNAKLAR}

APHA, AWWA, WPCF. (1992). Standard Methods for the Examination of Water and Wastewater, Sixteenth Edition, Washington DC.

Aqua Solutions 5 Inc. for the Township of Tiny. (2013). Township of Tiny Notice of Study Completion Lafontaine Beach Park, Beach Water Quality Improvements, Class Environmental Assessment Study. Project File Report Phases 1 and 2, December, Toronto, US.

Bodge, K.R. (2003). Design Aspects of Groins and Jetties. In: Advances in coastal structure design. Ed. R. Mohan, O. Magoon, M. Pirrello. American Society of Civil Engineers (ASCE). Reston, VA. ISBN 0-7844-0689-8. Pp. 181-199.

City of Los Angeles. (2001). Environmental Affairs Department. Cabrillo Beach Water Quality, Council File No. 99-0958, US.

Hanson, H. \& Kraus, N.C. (2003). Advancements in onelinem odeling of T-head groins (GENESIS-T). Journal of Coastal Research, SI(33), 315-323.W est Palm Beach (Florida), ISSN 0749-0208.

Hanson, H. \& Nicholas, C.K. (2001). Chronic Beach Erosion Adjacent to Inlets and Remediation by Composite (T-Head) Groins, US Army Corp.

Kerr, S.J. (1995). Turbidity And Suspended Sediments In The Aquatic Environment: an annotated bibliography and literature review. Ministry of Natural Resources, Southern Region Science \& Technology Transfer Unit, Technical Report TR008. 277 pp., Silt,. Ontario, Canada.

Martina, K., Volker, W. \& Gerhard, H. (2002). Laboratory concentration measurements for determination of mass exchange between groin fields and main stream Jirka. Institute for Hydromechanics, University of Karlsruhe, Karlsruhe, Germany.

Office of the Secretary. (2004). Water quality Rules and Regulations, Wyoming State, US.

Ping, W. \& Tiffany M., R. (2009). Performance of Upham Beach T-Groin Project and Its Impact to the
Downdrift Beach, Progress Report for the Period of October 2008 to April 2009, Department of Geology, University of South Florida, Tampa, FL 33620, May 30, US.

Port of Los Angeles Engineering Division. (2006). Inner Cabrillo Beach Bacterial Water Quality Improvement Project Implementation Plan, US.

Süme, V. (2003). The Study Of T Groins Rize Çayeli for Coastal Protection, Bildiri. Sixth. International Conference on Coastal \& Port Engineering in Developing Countries, COPEDEC VI, Colombo, Sri Lanka (Seylan).

Süme, V. (2007). Rize Sahilinde İyidere-Çayeli Arasında Yapılan "T" Mahmuzların Kıyı Koruma Açısından İncelenmesi. 4. Ulusal Klyı Mühendisliği Sempozyumu, Antalya.

Süme, V. (2011). Rize İyidere-Çayeli Arasındaki " $T$ " Mahmuzların Kıyı Koruma Açısından İncelenmesi, \&.Kıyı Mühendisliği Sempozyumu, İzmir, Türkiye.

Tauman, J. (1975). Bathing Beach Development by Means of Enclosing Scheme. Journal of the Assoc. of Eng. \& Arch and Symposium on Foreshore and Beach Development from the Coastal Engineering Aspect, Tel-Aviv, Israel.

Tauman, J. (1976). Enclosing Scheme For Bathing-Beach Development. Coastal and Harbour Eng. Ltd. Consulting Engineers, Ramat Hasharon, Israel.

Thomson, G. \& Swigler, D. (2013). Rehabilitation of the Breakers Hotel T-head Groin Field, Florida Shore $\&$ Beach Preservation Association, US.

University of Massachusetts Dartmouth School of Marine Science and Technology Massachusetts Department of Environmental Protection. (2004). Massachusetts Estuaries Project Linked Watershed-Embayment Model to Determine Critical Nitrogen Loading Thresholds for Popponesset Bay, Mashpee and Barnstable, Massachusetts. Final Report, September, US. 